\title{
Los entresijos paratextuales de un «cuento extraño» de Rosalía de Castro: El caballero de las botas azules*
}

\author{
The Paratexts of a «Cuento Extraño» by Rosalía \\ de Castro: El caballero de las botas azules
}

\author{
Noelia Iglesias Iglesias \\ Investigadora independiente \\ noelitaiglesias@hotmail.com \\ ORCID iD: http://orcid.org/0000-0003-3751-4067
}

\section{RESUMEN}

Al igual que ocurrió entre la crítica decimonónica, la novela de Rosalía de Castro El caballero de las botas azules. "Cuento extraño» (1867) sigue provocando hoy diversas exégesis. Su ambigüedad semántica y consecuente complejidad hermenéutica no se aprecian solo en los capítulos que componen esta enigmática obra, sino que comienzan en los propios paratextos que la enmarcan. El título y el subtítulo de la novela, así como su original prólogo proporcionan importantes claves interpretativas al receptor. El propósito del artículo es ofrecer una descripción bibliográfica de esta novela poco conocida en el panorama de la narrativa española de mediados del siglo XIX y, a partir de ahí, analizar sus elementos paratextuales en consonancia con su singularidad.

Palabras Clave: Rosalía de Castro; El caballero de las botas azules; paratextos; prólogo; título; subtítulo.

\section{ABSTRACT}

As it had happened among the nineteenth-century critics, Rosalía de Castro's novel $\mathrm{El} \mathrm{Ca}$ ballero de las Botas Azules. «Cuento Extraño» ('The Knight of the Blue Boots. Strange Story', 1867) still allows nowadays for many varied interpretations. Not only the chapters which form this enigmatic work show semantic ambiguity, but also the paratexts which frame it. The title, the subtitle, and the original prologue of the novel provide important keys for the reader. The purpose of this paper is to offer a bibliographical description of that novel, which is hardly known in the

* Agradezco a María do Cebreiro Rábade Villar, investigadora especialista en la vida y obra de Rosalía de Castro, su generosa labor de guía en este mi primer viaje por los senderos rosalianos. 
middle nineteenth-century prose fiction, and to analyze its paratextual elements in line with its singularity. Subtitle.

Key words: Rosalía de Castro; El caballero de las botas azules; Paratexts; Prologue; Title;

«En el panorama que ofrece la novela española del siglo XIX esta obra se individualiza poderosamente a causa de su carácter insólito y tan original, como que no hay ninguna otra en toda esa centuria con la que quepa compararse». Con estas palabras reivindicaba Antón Risco (1975: 113) el singular valor de la novela El caballero de las botas azules de Rosalía de Castro (1837-1885), publicada en 1867. La autora tiñe intencionadamente esta desconcertante ficción alegórica de una ambigüedad semántica — la cual da lugar a una indudable complejidad hermenéutica - que la aleja del canon literario decimonónico.

Al igual que ocurrió con la crítica en el siglo XIX, este relato rosaliano sigue provocando diversas exégesis y apreciaciones en la actualidad, si bien continúa siendo poco conocido dentro de la producción literaria de la escritora gallega, así como en la narrativa española de la época ${ }^{1}$. Las dificultades a la hora de abordar la interpretación de El caballero de las botas azules y, a la par, su atractivo, no se advierten solo en los capítulos que forman esta enigmática pieza, sino que comienzan en los propios paratextos que la enmarcan, que serán estudiados en este artículo ${ }^{2}$, en consonancia con la originalidad de la novela, la cual no encaja en el modelo realista canónico construido a partir de aquel período $^{3}$. Este análisis pretende inscribirse en las investigaciones más o menos recientes que giran alrededor del examen de los paratextos en la obra literaria de Rosalía de Castro.

El objeto de estudio del presente artículo radica tanto en la revisión de aquellos elementos paratextuales que transmiten una información pura, tales como los nombres de la novelista y el editor o el año y la ciudad de publicación, como aquellos que dan a conocer una intención autoral; en este caso, el título, el subtítulo, el prefacio que antecede al texto -el cual ha sido analizado en detalle por Fernández-Pérez Sanjulián (1986) - o la cita que encabeza uno de

${ }^{1}$ Rábade Villar (2013: 50) revisa la bibliografía crítica en torno a la consideración de la novela.

${ }^{2}$ Por paratexto se entiende aquel «acompañamiento, de amplitud» de «un cierto número de producciones, verbales o no, como el nombre del autor, un título, un prefacio, ilustraciones, que no sabemos si debemos considerarlas o no como pertenecientes al texto, pero que en todo caso lo rodean y lo prolongan precisamente por presentarlo» (Genette, 2001: 7).

${ }^{3}$ Para la recepción diacrónica de la novela puede acudirse a Rodríguez-Fischer (Castro, 2000: 19-79). Han de añadirse las recientes aportaciones interpretativas de Helena Miguélez-Carballeira (2012: 121-138) e Isabel Clúa Ginés (2012: 159-177). 
los capítulos ${ }^{4}$. El orden en el que cada paratexto será examinado vendrá determinado por su aparición espacial en la novela. Dado que realizaré una aproximación a la mencionada novela desde el examen de los componentes que circundan el texto y lo presentan exteriormente, se antoja útil empezar con una breve descripción bibliográfica de su primera edición:
Encuadernación holandesa deteriorada colocada a posteriori-Formato de $23 \times 16$ - Hoja de guarda-Anteportada-Portada: El CABALLERO / DE / LAS BOTAS AZULES. / Cuento extraño / por / Rosalía Castro de Murguía. / Lugo. / Imprenta de Soto Freire, editor. / Calle de San Pedro, núm. 31. / 1867.-Prólogo autoral titulado UN HOMBRE Y UNA MUSA (pp. V-XXXIII) / EL CABALLERO DE LAS BOTAS AZULES (pp. 1-313) -2 hojas con bibliografía de la casa editora (entre ella, anuncio de la publicación del primer tomo completo y de veinticuatro entregas del segundo volumen de la Historia de Galicia de Manuel Murguía, junto a la noticia de la segunda edición aumentada de Cantares gallegos de Rosalía Castro de Murguía como obra en prensa, pp. 353 y 356)—Hoja de guarda-Contracubierta.

Se ha manejado el ejemplar con signatura 20889 depositado en los fondos de la Real Academia Galega, procedente de la biblioteca particular de doña Emilia Pardo Bazán, cuya firma aparece en la portada (Ilustración 1).

Lejos de albergar una ilustración que represente al personaje protagonista de la historia o sus botas, como sucede en algunas ediciones modernas de la novela ${ }^{5}$, la portada de la edición príncipe está presidida por el título, con tipos de mayor tamaño y con letra negrita en el sintagma «las botas azules». El título se localiza en otros lugares casi obligados del libro, como en la anteportada, en donde se aprecia que la frase nominal «las botas azules» vuelve a ser de mayor dimensión que «el caballero», o en las cornisas, es decir, en la parte superior de cada página del texto de la novela: en las pares se lee «EL CABALLERO» y en las impares, «DE LAS BOTAS AZULES». La anteportada conserva el cuño que indica la posición física que ocupaba el ejemplar en la biblioteca privada de Pardo Bazán (Ilustración 2).

El ejemplar proveniente de la biblioteca pardobazaniana carece de la cubierta genuina del libro, que no se ha conservado bajo la encuadernación holandesa añadida a posteriori, la cual se halla bastante deteriorada en la actualidad. Llama la atención que, en el lomo de dicha cubierta agregada, el título aparece abreviado («BOTAS AZULES»), lo que indica que para quien encargó la cubierta (acaso doña Emilia) predominó el recuerdo de las significativas botas azules del caballero sobre este mismo. Otra razón material pudo contribuir a la reducción del título en el lomo: la palabra caballero está compuesta por nueve letras y habría quedado comprimida y menos elegante en el lomo.

\footnotetext{
${ }^{4}$ Para las distintas clases de paratexto se sigue también a Genette (2001: 15).

5 Ver las diferentes ediciones de El caballero de las botas azules (Castro, 1931, 1973, 2000 y 2013).
} 


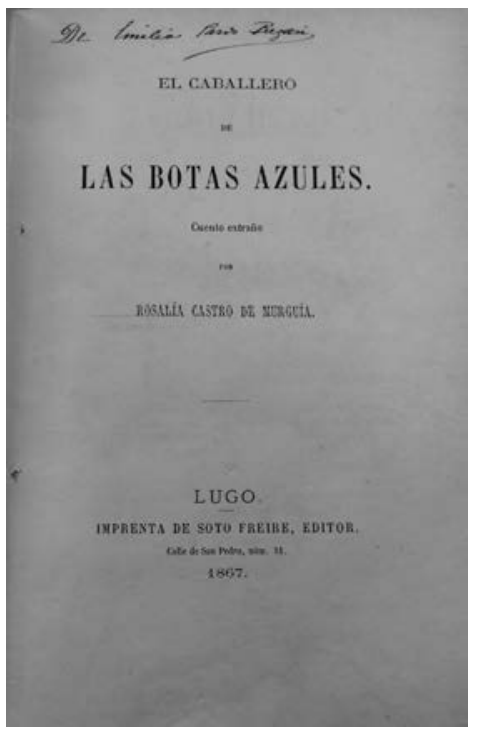

Ilustración 1: Portada de la primera edición de El caballero de las botas azules de Rosalía de Castro (Lugo, 1867). Ejemplar de Emilia Pardo Bazán, depositado en la biblioteca de la Real Academia Galega (en adelante RAG) (sign. 20889), del que se extraen también las imágenes siguientes, a menos que se indique lo contrario

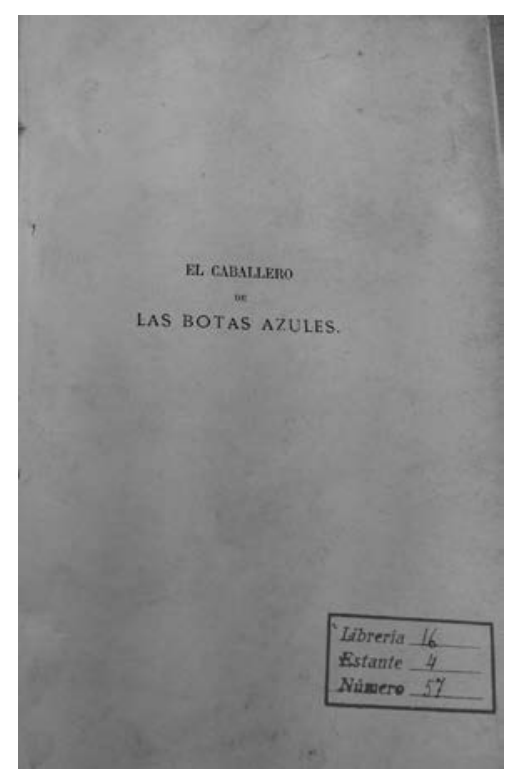

ILUSTRACIÓN 2: Anteportada 


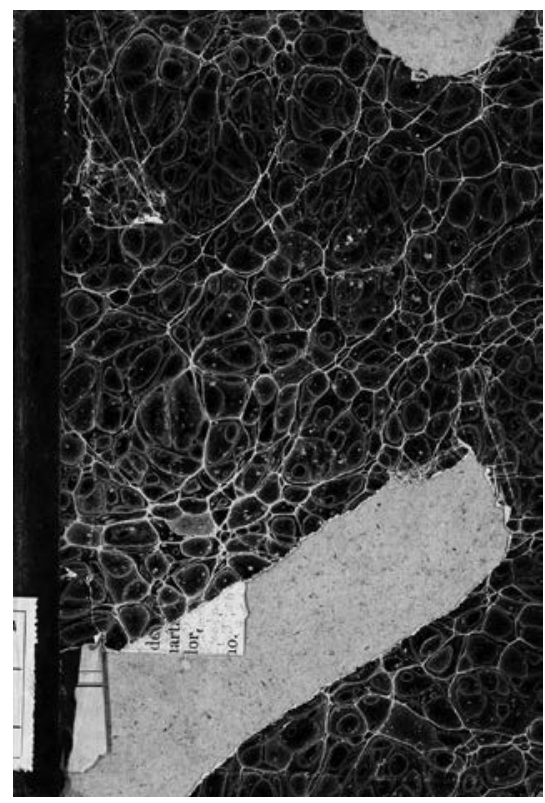

ILUSTRACIÓN 3: Cubierta con encuadernación holandesa colocada a posteriori

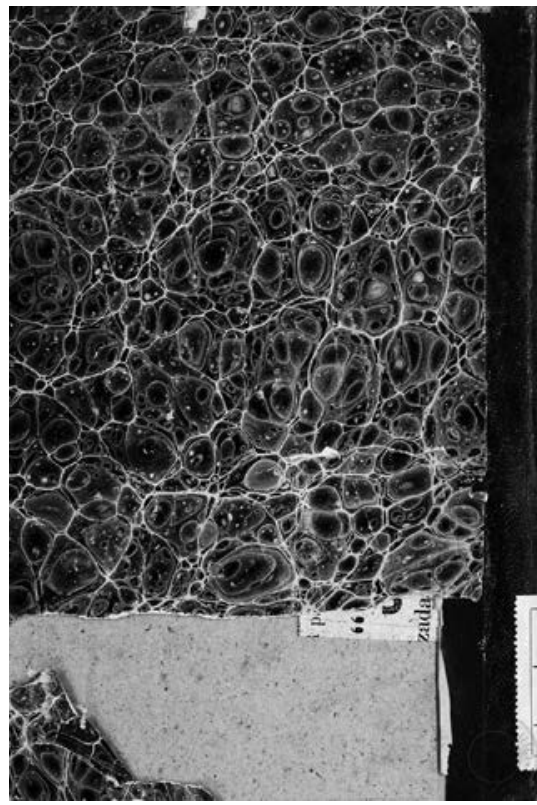

ILUSTRACIÓN 4: Contracubierta con encuadernación holandesa colocada a posteriori 


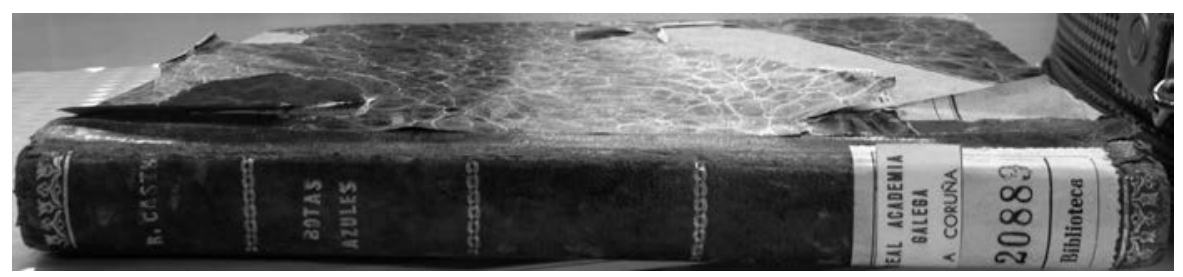

ILUSTRACIÓN 5: Lomo de la cubierta y encuadernación holandesa colocada a posteriori

En la biblioteca del Monasterio de San Juan de Poio, en Pontevedra (Galicia, España), se registra el único ejemplar localizado de la novela cuya encuadernación original, en rústica color rosado - un poco dañada especialmente en la parte superior-, ha llegado a nosotros bajo la nueva encuadernación holandesa a la que fue sometida (Ilustración 6).

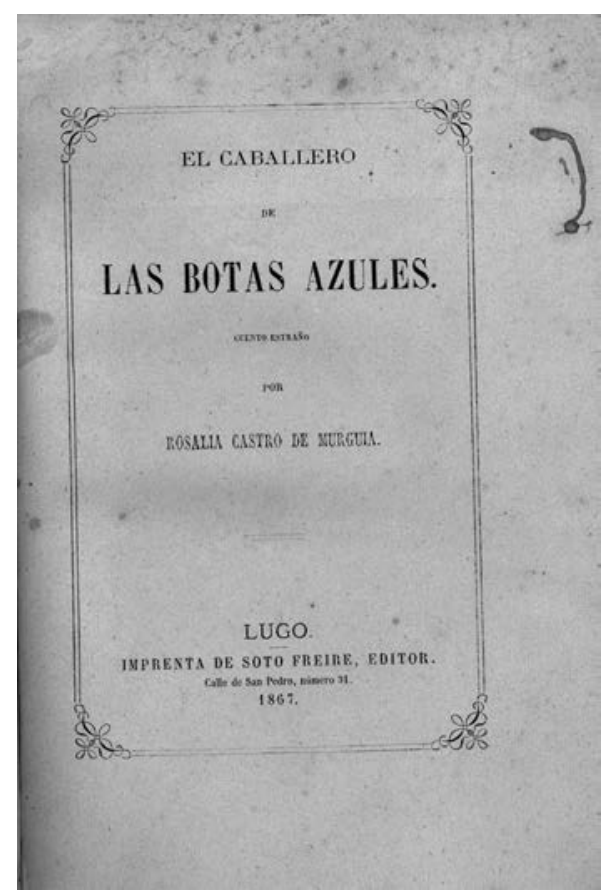

ILUSTRACIÓN 6: Cubierta original de la primera edición de El caballero de las botas azules de Rosalía de Castro (Lugo, 1867). Ejemplar de Antonio Rey Soto, depositado en la biblioteca del Monasterio de San Juan de Poio

(sign.: R. S. 13/3 11) 


\section{EL TÍtUlo}

De acuerdo con las diferentes categorías que establecía en el nivel semántico Leo H. Hoek, uno de los fundadores de la titulogía moderna, El caballero de las botas azules se englobaría dentro de los títulos subjetuales, al aludir al protagonista del texto, tipología tradicionalmente mayoritaria (1981: 206), ya desde los autores grecolatinos. Esta taxonomía titulógica, que predomina en los encabezados de la novela decimonónica y en la obra prosística de Castro - $L a$ hija del mar (1859), Flavio (1861), El cadiceño (1866) y El primer loco (1880) - , se caracteriza por designar al personaje central de la trama, aunque este no es nombrado siempre de igual manera. De esta suerte, la escritora rehúsa titular su relato El duque de la Gloria (113) ${ }^{6}$, El esperado (127), El duende azul (131) o El caballero de la capa negra (276) - calificativos, entre otros, con los que el protagonista es denominado a lo largo del texto- para decantarse por la referencia al personaje a través de un sobrenombre basado en el rasgo externo primordial que le identifica por metonimia: las botas azules.

Como primer signo de la novela, el título El caballero de las botas azules genera una expectación en el receptor, incapaz en principio de reconocer ni en el prólogo ni en las líneas iniciales del capítulo inaugural al personaje aludido. Sin embargo, según avanza aquel primer capítulo, se brinda la primera descripción del duque de la Gloria, al que rápidamente el lector identifica con la figura sugerida en el título por la mención de sus botas azules:

Un joven y elegante caballero, vestido de negro, que calzaba unas botas azules que le llegaban hasta la rodilla, y cuyo fulgor se asemejaba al fósforo que brilla entre las sombras [...] Sus botas, maravilla no vista jamás, parecían hechas de un pedazo del mismo cielo (112).

A pesar de que el extraño atavío del duque de la Gloria se completa con un águila blanca colocada como corbata y con una varita negra que termina en un sonoro cascabel, elementos en cuya mención y descripción se complace Castro en varias ocasiones (cap. I, II, VI, VII, XXIII...), destaca en el título únicamente las botas azules del personaje. Esta decisión seguramente fue tomada por la autora en las primeras fases de su proceso creativo, a juzgar por la referencia al encabezado en varios momentos metaficcionales de la narración, en los que realiza, con evidente ironía, autoalusiones a su obra. Cual dramaturgo que quebranta la cuarta pared, la novelista lleva a cabo una estrategia de ruptura mediante la metalepsis, como muestran los pasajes que siguen, portadores de una manifiesta intención humorística al dar cuenta del escaso valor literario de la propia pieza: «Y he aquí cómo, en guerra con el sentimentalismo,

${ }^{6}$ Se alude de aquí en adelante a la edición de Rodríguez-Fischer (Castro, 2000) indicando únicamente las páginas. 
puerta de escape de todos los escritores tan ramplones como el autor de $E l$ caballero de las botas azules...» (137); «me ha indignado la reciente lectura de una novela desconocida que lleva por epígrafe: El caballero de las botas azules...» (314) y "Ayer decía de ella entre otras cosas. "Érase una novela titulada El caballero de las botas azules"...» (314) ${ }^{7}$. Asimismo, varios personajes, e incluso la misma voz narrativa, nombran al duque de la Gloria mediante el sintagma «caballero de las botas azules» $(230,258,271$ y 283), apodo que acepta el propio protagonista (186). Esta reiteración del título de la novela a lo largo del texto contribuye, cual leitmotiv, a concentrar la atención del receptor en torno de dicho objeto (las botas azules), el cual marca un centro en el texto al constituir el elemento tematizado y subrayado en el paratexto identificativo de la pieza ${ }^{8}$.

La insistente referencia a las exclusivas botas azules del protagonista, así como a su poder de asombrar y provocar interés irreprimible en los demás, entroncan con el sentido satírico con el que la autora construyó su relato ${ }^{9}$. Al igual que hará Galdós años más tarde en La de Bringas (1884), Castro retrata a una sociedad capitalista dominada por las modas - son continuas las menciones de la vestimenta de los personajes, aspecto no infrecuente en la literatura decimonónica (Díaz Marcos, 2006: 136) — y, en definitiva, por la importancia de las vanas apariencias, que asola especialmente a las clases altas y medias, incapaces de ser sorprendidas si no es con un extravagante reclamo exterior. De ahí que las cuasi mágicas botas azules — confeccionadas en Asia, origen que refuerza el carácter estrambótico de quien las calza y el ansia de exotismo de los otros - conforman el modo que posee el duque de la Gloria de afirmar su singularidad ${ }^{10}$. Esto es, se erigen en un símbolo de distinción, lo que la mayoría de los personajes lucha por conseguir a toda costa — cada cual a su manera-, incluido el todavía anónimo y genérico Hombre del prólogo, que solicita a la Musa Novedad que le conceda la inmortalidad a través de la

${ }^{7}$ Ya en la primera edición, el título aparece siempre en cursiva en estos pasajes autorreferenciales, para cuyo estudio se remite a Cabo (2013).

8 Para Mecke (2004: 31), «El título tiende el primer puente entre el lector y la obra, y asume, con ello, una significativa tarea en la comunicación literaria». Eco (1985: 6) se dirige más allá al sostener que un título «ya es una clave interpretativa».

9 Charnon-Deustch (1999: 18) analiza la representación del deseo en la novela y concluye que «Desde la perspectiva del deseo El caballero de las botas azules es uno de los textos más fértiles de la literatura española, un catálogo de las muchas insatisfacciones y exigencias atribuibles a una sociedad decadente cuya búsqueda de placer nunca lleva a la satisfacción».

10 Cual fetiche fálico freudiano, «al concentrar tanta atención en las relucientes botas del duque, Castro pone de manifiesto la manipulación del deseo y lo absurdo de su objetivo material aún más que la tragedia del deseo ontológico insaciable» (Charnon-Deustch, 1999: 14). 
fama póstuma. De esta forma, el look del duque de la Gloria anticipa los cambios históricos e ideológicos que representa su emblemática figura.

La ironía y la sorna con que Castro orienta su texto alcanzan al propio título, ya que concede a su figura literaria — un codicioso escritor fracasado (el futuro duque de la Gloria), que ha trepado por el escalafón social a base de estrategias no demasiado éticas - la condición de caballero. Esta etiqueta contrasta con la idéntica designación de otros personajes, como el caballero de la Albuérniga, debida supuestamente a una estirpe de cierto abolengo de la que carece el protagonista de la novela, de acuerdo con lo que informa la Musa en el prólogo (94-100).

Es sabido el cuño cervantino y particularmente quijotesco de El caballero de las botas azules, uno de cuyos designios esenciales, la invectiva de la novela en boga en España a mediados del siglo XIX y, por extensión, de la sociedad en la que surge, perpetúa el propósito de don Miguel de satirizar la novela caballeresca de moda en su tiempo y a sus contemporáneos ${ }^{11}$. Ya desde el título, Rosalía de Castro rinde un homenaje al célebre autor — al que acude varias veces en su texto-, como apuntaron Rodríguez-Fischer (Castro, 2000: 36-42) o Rábade Villar (2013: 53), con el fin de que se relacione a aquel nuevo justiciero de las botas azules, «un héroe de nuestros tiempos», con el manchego caballero de la triste figura ${ }^{12}$. En consecuencia, como tantos títulos literarios, el de esta novela de Castro no solo dialoga con su texto, sino con una tradición anterior consolidada y conocida por el receptor.

Aparte de esta alusión implícita a la célebre figura quijotesca, quizás puede atisbarse también una relación intertextual entre el apodo del protagonista de la escritora gallega y el también cervantino caballero del verde gabán, como sugirió Rodríguez-Fischer (Castro, 2000: 23). La misteriosa identidad y puntual aparición en la novela barroca de este misterioso personaje casan bien con la llegada estelar del duque de la Gloria a la corte madrileña. Desde la perspectiva semántica, los dos apelativos se hallan próximos entre sí al apuntar a un elemento representativo de la vestimenta de uno y otro caballero (gabán/botas) y a su color, no menos significativo (verde/azul). Seguramente Castro eligió este último tono para las botas de su ente de ficción para otorgar a su atuendo espiritualidad y alejamiento del mundo terrenal ${ }^{13}$.

${ }^{11}$ En palabras de Francisco Rodríguez: «A literatura é aquí símbolo, síntoma dunha realidade [...] A nova literatura [...] representa a aspiración a unha nova sociedade, de marcado signo moral anti-burgués, por máis que sexa utopista» (cito por Fernández-Pérez Sanjulián, 1986: 480).

${ }_{12}$ Nótese que ambos nombres cervantino y rosaliano forman un perfecto endecasílabo.

${ }^{13}$ En su Diccionario de iconografia y simbología, defiende Revilla que el azul suele representar el desprendimiento de lo mundano y el acercamiento o la identificación con lo sobrenatural o divino (2010: 76). Risco insiste también en las ideas de elevación que sugieren las botas azules, «confirmadas [...] por el título que se incorpora de Duque de la Gloria» 
En la elección de un complemento externo como las botas y, sobre todo, su color azul, no debe pasarse por alto la reveladora existencia del fenómeno social dieciochesco de las blue stockings, en inglés, o bas-bleus, en francés (literalmente, 'media azul'). Con dichas etiquetas era conocida una comunidad femenina de intelectuales literatas que reivindicaron el derecho de la mujer a escribir, a pensar y a conquistar otros roles más allá de los tradicionales que les había asignado la sociedad patriarcal, y que eran satirizadas precisamente por este hecho. Kathleen March (2012: 38-39) sugiere que tal vez Rosalía de Castro estuviera al corriente de dicho movimiento social feminista: «As Blues, Bleus, Azuis tiñan representación verbal e plástica, moi acesíbel á literata galega».

En efecto, este hipotético conocimiento del debate europeo sobre las literatas, bluestockings o New Woman por parte de la novelista puede contribuir a esclarecer por qué eligió el color azul para las botas - próximas a las mediasde su caballero, destacadas en el título de la obra: «as botas do protagonista eran azuis por todo o que significaba de literata; e [...] poden ser outro disfrace empregado por Castro, que se cadra coñecía os debuxos, as imaxes, que se mofaban das bas bleus en Francia» (March, 2012: 38). No en vano, la citada especialista en Rosalía de Castro Kathleen March encabeza con el título de Bluestockings la traducción inglesa del manifiesto rosaliano de «Las literatas. Carta a Eduarda» (Castro, 1997) — publicado originariamente en el Almanaque de Galicia en 1866, por Soto Freire, el mismo editor de El caballero de las botas azules, como veremos - . Sin duda, este escrito deliberadamente feminista entronca de lleno con la mencionada corriente, cuyas ideas ratifica la escritora en la novela que nos ocupa, en la que existe una feroz crítica al parasitismo y superficialidad femeninas en las clases media y alta.

Cabe señalar que la autora proporciona un apodo de uso privado a su novela cuando, en una carta dirigida a su marido Manuel Murguía, que ha llegado a nosotros de manera fragmentaria y sin fecha, escribe: «Las damas verdes de Jorge Sand tienen muchísima semejanza en cierto estilo con mi joven azul. ¿Qué te parece? Van a decir que he querido imitarla» (Castro, 1977: 1005). Casualidad o no, la traducción de Les Dames Vertes de la escritora francesa George Sand es vertida por primera vez al español en 1863 como Las damas verdes, paratexto identificativo que se asemeja al título de la novela rosaliana, tal como ella misma manifiesta de modo implícito en la alusión a ambas obras: «Las damas verdes»/ «mi joven azul».

(1975: 119). Otros personajes y títulos áureos juegan con la alusión a un rasgo exterior y a su color, como ocurre en la comedia de Tirso de Molina Don Gil de las calzas verdes. Davies (1988) sugiere la posible influencia de títulos de novelas históricas como El caballero verde, novela caballeresca (1842) o El caballero de Calatrava (1863) de Benito Vicetto, a quien Castro dirige algunas de sus mofas, según la estudiosa. 


\section{El SUbTítulo}

Un anexo, con tamaño mucho menor, acompaña al título en la portada y cubierta de la primera edición de la pieza: «cuento extraño», subtítulo cuya primera palabra enlaza directamente con el género narrativo de la obra ${ }^{14}$. En efecto, la autora vincula su relato desde el principio con el universo de lo alegórico y lo simbólico a través de su categorización como cuento y no como novela ${ }^{15}$. Mediante este breve apunte paratextual, Castro sitúa El caballero de las botas azules fuera de los parámetros literarios del realismo, conque la elección de aquel subtítulo alberga toda una declaración de intenciones. A través de aquella simple marca genérica intencionada pretende que, desde el inicio, el receptor acepte la historia como un relato puramente fantástico. Asimismo, puede deducirse de los significativos subtítulos de las novelas rosalianas que «la autora no se sentía cómoda o segura» en el género novelístico (Vilavedra, 2012: 48-49). Recuérdese que, en su texto «Las literatas. Carta a Eduarda», había sentenciado: «novelista, es decir, lo peor que puede ser hoy una mujer» (Castro, 1866: 57).

Pero no se detiene ahí y denomina a su cuento extraño, adjetivo que se reitera en los veinticuatro capítulos que componen la novela, atribuido al duque de la Gloria y sus particularidades externas, aspecto que actualiza en cierta manera una y otra vez el subtítulo de la obra ${ }^{16}$. La escritora es consciente de que su parábola causará desconcierto en los lectores y desarrolla esta idea de modo metaficcional en su prólogo, en el momento en el que la Musa acepta otorgar al Hombre, un «tipo acabado de los que hoy por el mundo corren y viven y triunfan» (92), su deseo de fama eterna. Nótese que en el siguiente fragmento tacha por primera vez de extraña la que va a ser la apariencia física del futuro caballero: «para que puedas cumplir tus gloriosos votos, solo falta que te instruya en mi ciencia, dándote parte de mi manera de ser y una apariencia extraña y maravillosa» (105). Trece años después de la publicación de El caballero de las botas azules, Castro acude de nuevo a la etiqueta cuento extraño tras el título de su última novela, El primer loco, en la que obvia también las fórmulas literarias realistas predominantes en aquel período.

${ }^{14}$ La edición de El caballero de las botas azules publicada en Madrid, por la editorial Magisterio Español en 1973 y con introducción de Domingo García-Sabell no edita ni en la portadilla, ni en la contraportada o en la portada la indicación paratextual «Cuento extraño». Se trata de «un subtítulo jánico, que mira tanto hacia atrás - el título ya enunciado- como hacia adelante - la novela a punto de iniciarse-, anticipando un aspecto fundamental de esta obra rosaliana: su rareza, su unicidad» (Castro, 2000: 25).

15 Así lo ha entendido también Risco (1986: 453), quien subraya el componente fantástico de la obra.

${ }^{16}$ Son empleados también con frecuencia otros calificativos pertenecientes al mismo isotopo que extraño, ligados al caballero y a sus rasgos exteriores: raro, extravagante, singular o incomprensible. 


\section{El NOMBRE DE LA AUTORA}

Tras el subtítulo en la portada, leemos el nombre de la autora, que aporta dos marcas de identidad cardinales. El rasgo relevante introducido por su nombre de pila (Rosalía) es su pertenencia al sexo femenino, aspecto que posee sin duda pertinencia temática decisiva en toda la producción literaria rosaliana, incluida esta novela, en la que critica vivamente la ociosidad del sector femenino de la nobleza y la burguesía ${ }^{17}$. El segundo dato destacable que se desprende de los apellidos de la escritora es su voluntad de aunar en su firma su apellido de soltera (Castro) y el de casada (de Murguía) - lo mismo hace en la primera edición de El cadiceño o en la de El primer loco-, que la ligan directamente con su esposo, el intelectual galleguista Manuel Murguía, muy conocido ya en 1867 en los círculos académicos y con quien había contraído matrimonio en 1858 .

\section{LA CIUDAD DE PUBLICACIÓN Y LA IMPRENTA}

Como se comprueba en la portada de la edición príncipe, la novela fue impresa en las prensas de Soto Freire en Lugo, ciudad que aparece allí curiosamente en un tipo de mayor tamaño que el nombre del editor, el año o que incluso el subtítulo y la autora del libro. Manuel Soto Freire, figura notable en la historia de la imprenta y la prensa lucense, había emprendido igualmente la impresión del relato rosaliano El cadiceño, en uno de los famosos Almanaque de Galicia un año antes, y los tomos primero y segundo de la Historia de Galicia de Manuel Murguía en 1865 y 1866, respectivamente ${ }^{18}$.

De hecho, en la biblioteca de la Real Academia Galega, se conserva correspondencia de Soto Freire a Castro datada en aquellos años, mayoritariamente referida a su relación comercial, en la que la escritora actúa en ocasiones como mediadora entre el editor lucense y su marido, embarcado en sacar adelante las entregas de los volúmenes de la Historia de Galicia. Este epistolario podría convertirse en objeto de estudio concreto de otro artículo científico, dado el interés de la información que de él se extrae. En este caso, se atenderá únicamente a los pasajes que conciernen al proceso de edición y posterior distribución de El caballero de las botas azules. Las líneas referidas a la novela,

17 Para la perspectiva feminista en la narrativa de Castro puede citarse a March, quien ahonda en el caso específico de la novela que nos ocupa (1994: 231-311).

${ }^{18}$ Consúltese Rielo Carballo (1982: 91-187) para una breve semblanza de Soto Freire y para un catálogo de los impresos salidos de sus prensas. Un estudio más detallado acerca de la biografía y la obra del mencionado impresor lo ofrece Barreiro Fernández (Soto, 1998: 7-27), responsable de la introducción al ensayo bibliográfico póstumo La imprenta de Galicia de Soto Freire. 
pertenecientes a 1867, se centran en diversos asuntos; entre ellos, en los envíos de pruebas de la novela, sobre todo en cartas de mayo y junio de aquel año.

En una epístola datada el once de marzo de 1867, Soto Freire se lamenta por la entrada en vigor de una ley de imprenta que obligaba a que la pieza debiera ser revisada oficialmente por un fiscal, acción que trataría de impedir el editor, si bien insiste en que aquella figura burocrática no encontraría nada sospechoso, pensando tal vez en la sátira social alegórica que contiene el texto, no perceptible con facilidad por todo tipo de lectores (Ilustración 7): «Ayer ha llegado una nueva ley de imprenta, que nos pone muchas trabas, y no hay remedio sino dar la novela al fiscal; yo cuidaré de que no le toque, si no encuentra nada, como supongo» ${ }^{19}$.

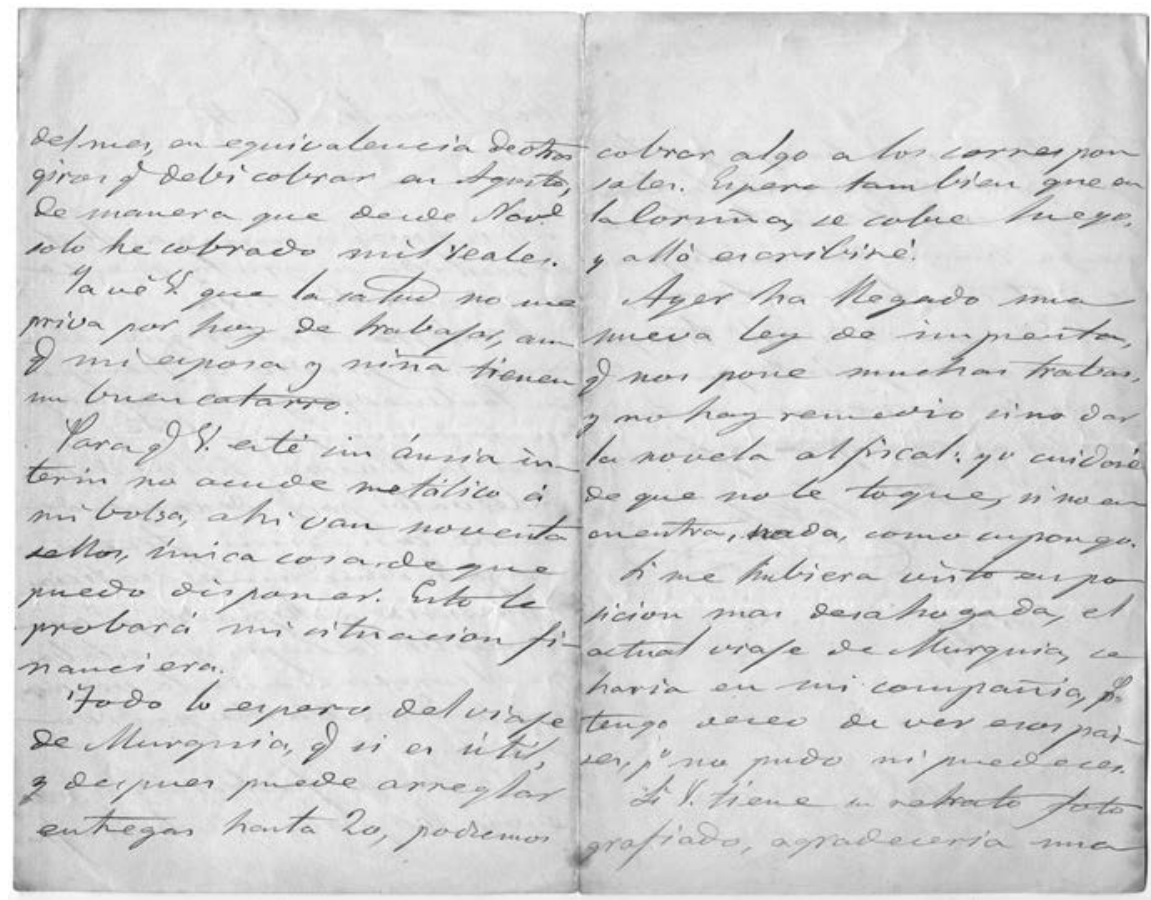

ILUSTRACIÓn 7: Carta de Soto Freire a Rosalía de Castro (11/03/1867), depositada en la biblioteca de la RAG

19 En las transcripciones del epistolario se desarrollan las abreviaturas (como usted o que en lugar de $U$. o q), pero se mantiene la puntuación original o las incoherencias sintácticas, tales como la que se produce en el segundo párrafo de la segunda carta que se adjunta: «en un pueblos». 
En otra carta, fechada el veintiocho de mayo de aquel año, Manuel Soto Freire se justifica ante la imposibilidad de apresurarse con la edición de la novela por reducción de personal, así como responde a las vacilaciones de la autora sobre si la novela se divulgaría entre los estudiantes — quizás el público al que le interesaba llegar a Rosalía de Castro-. Asimismo, se pone de manifiesto el interés de ambos por conseguir éxito económico con la publicación, la cual impulsaría el editor con la estrategia comercial de añadir la etiqueta de «segunda edición»a la mitad de los ejemplares editados (Ilustración 8) ${ }^{20}$ :

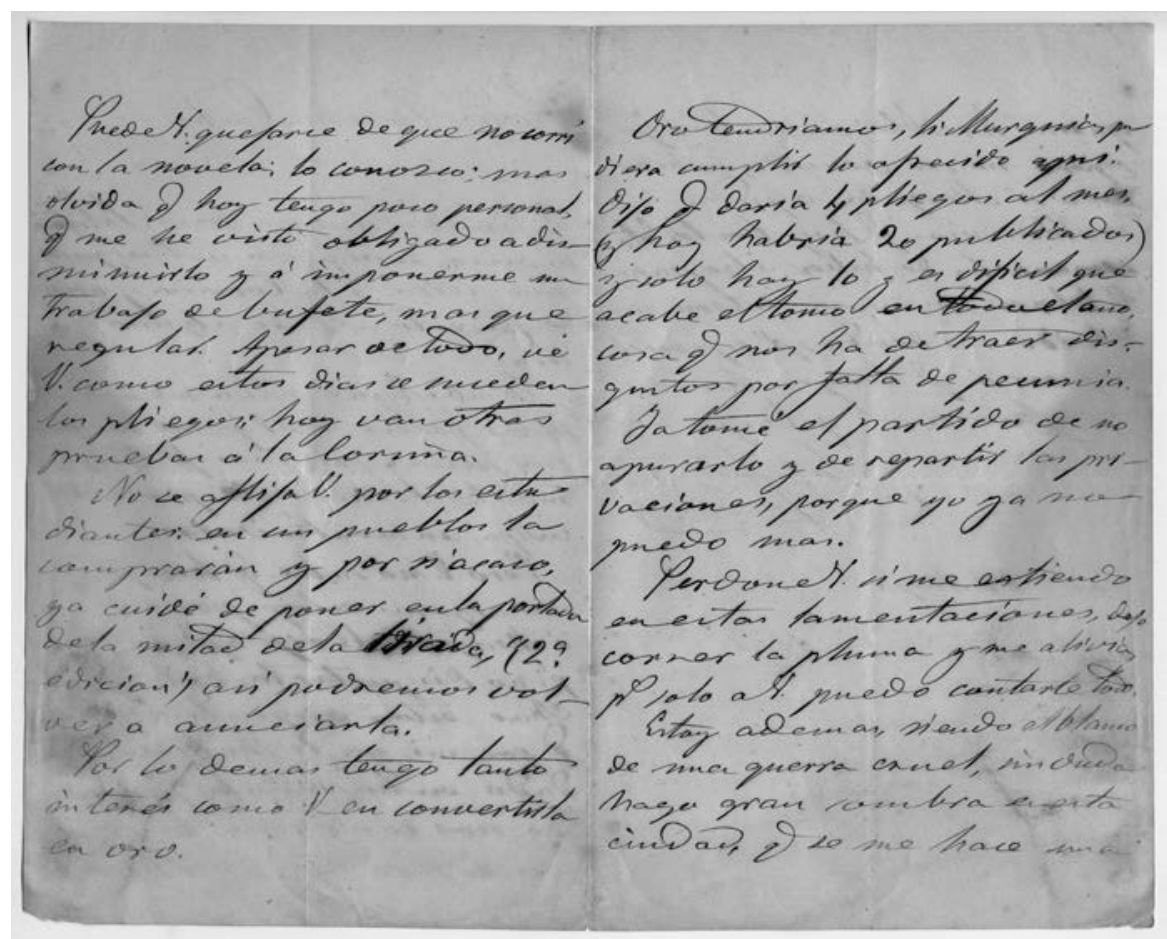

Ilustración 8: Carta de Soto Freire a Rosalía de Castro (28/05/1867), depositada en la biblioteca de la RAG

${ }^{20}$ Precisamente la edición facsimilar de El caballero de las botas azules publicada en Vigo por el Patronato Rosalía de Castro en 1989, junto a La hija del mar y con prólogo de Francisco Fernández del Riego, recoge la segunda edición de la obra, cuya cubierta solo se diferencia de la princeps en la adición de la mencionada etiqueta «segunda edición» tras el nombre de la autora (Castro, 1989). 
Puede usted quejarse de que no corrí con la novela; lo conozco; mas olvida que hoy tengo poco personal, que me he visto obligado a disminuirlo y a imponerme un trabajo de bufete, más que regular. A pesar de todo, ve usted cómo estos días se suceden los pliegos; hoy van otras pruebas a la Coruña.

No se aflija usted por los estudiantes; en un pueblos la comprarán y por si acaso, ya cuidé de poner en la portada de la mitad de la tirada "2." edición"; así podremos volver a anunciarla.

Por lo demás tengo tanto interés como usted en convertirla en oro.

En una epístola posterior, del veinticuatro de diciembre de 1687, Soto Freire insiste en que pronto se conocerán los resultados de la comercialización de El caballero de las botas azules en la capital, en donde destaca la alusión a la obra mediante un título abreviado (Ilustración 9): «Luego sabremos la venta que en Madrid han tenido las botas azules».

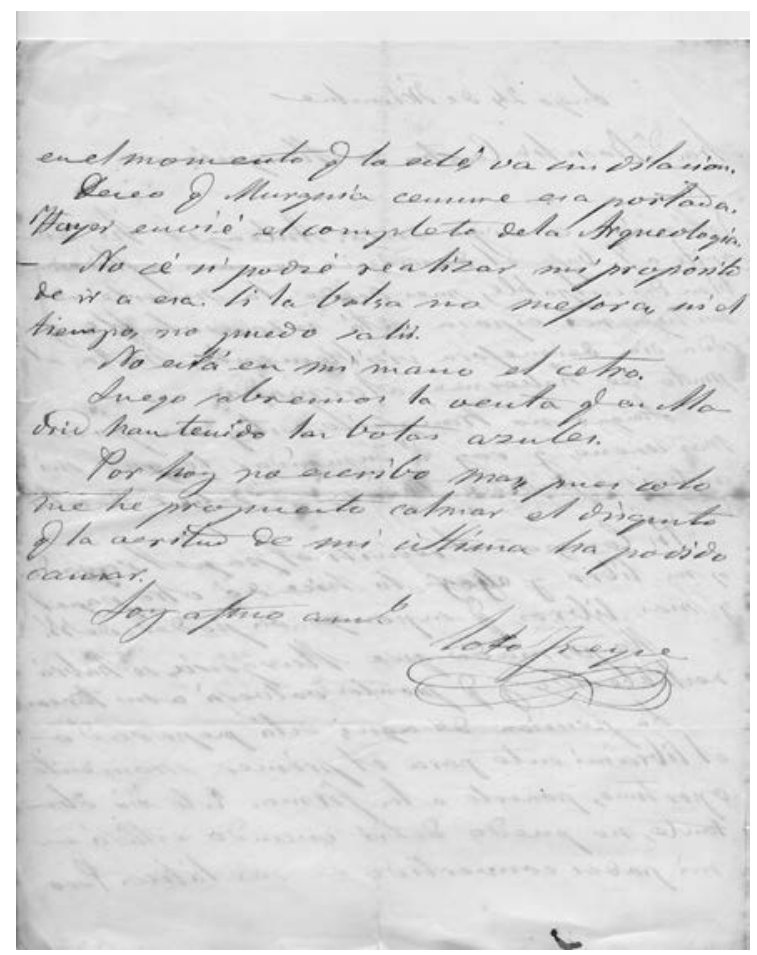

ILUSTRACión 9: Carta de Soto Freire a Rosalía de Castro (24/12/1867), depositada en la biblioteca de la RAG 


\section{EL AÑO DE PUBLICACIÓN}

El caballero de las botas azules fue publicada en 1867, año que precede a la revolución liberal de «la Gloriosa», en 1868, hecho histórico asociado a los albores de la novela moderna para la períodología literaria del siglo XIX ${ }^{21}$. De acuerdo con la importancia de la datación de cualquier obra literaria (Genette, 2001: 12), la fecha en la que ve la luz el relato de Castro resulta bien significativa a ojos del receptor moderno conocedor de la historia de España, cuya lectura se verá influida por tal información, sobre todo teniendo en cuenta que el tiempo representado en la novela parece coetáneo al de su publicación, lo que percibirían también sus primeros lectore ${ }^{22}$. Sin duda, la cercanía de la aparición de la novela con el estallido de la denominada «revolución del 68», la sociedad retratada en ella, así como el propósito de transformación social subyacente en el texto, contribuyeron a que fuera descifrada a menudo en clave política ${ }^{23}$.

\section{EL PRÓLOGO}

El prólogo autoral ficticio que precede a El caballero de las botas azules se alza en el único elemento paratextual hasta ahora descrito que no se dirige al público en general, sino específicamente a los lectores del texto. En su encabezamiento, la novelista prescinde del término prólogo o similares para titularlo «UN HOMBRE Y UNA MUSA», rótulo que se repite en las cornisas de este texto: UN HOMBRE, en las páginas pares; Y UNA MUSA, en las impares (Ilustración 8).

El título «UN HOMBRE Y UNA MUSA» recoge las dos figuras abstractas que protagonizan este prefacio dialogado y prepara al lector hacia el alcance alegórico. En efecto, el proemio — cuya estructura es tripartita, como señala la numeración - se aleja del modelo de prólogo-manifiesto que precede a otras piezas rosalianas, como el de Follas novas o La hija del mar. Por el contrario, entronca con las características que este paratexto poseía en las obras clásicas,

${ }^{21}$ Ver Romero Tobar (cito por Rábade Villar, 2013: 65, nota n. ${ }^{\circ}$ 4).

${ }^{22}$ Frente a la habitual localización geográfica de sus obras en Galicia, por primera vez, Rosalía de Castro sitúa la trama de una de sus piezas fuera de aquel territorio, en concreto, en Madrid. De hecho, a la autora le interesa ubicar espacialmente la acción de El caballero de las botas azules desde la primera línea del texto: «Hay en Madrid un palacio extenso y magnífico...» (108).

${ }^{23}$ Rábade Villar (2013: 51) vincula precisamente a la alegoresis «el protagonismo adquirido por el atuendo fantástico del caballero». Consúltese Rodríguez (2011: 202-239) y Rábade Villar (2013) para el análisis de la novela como alegoría del cambio social y político. 


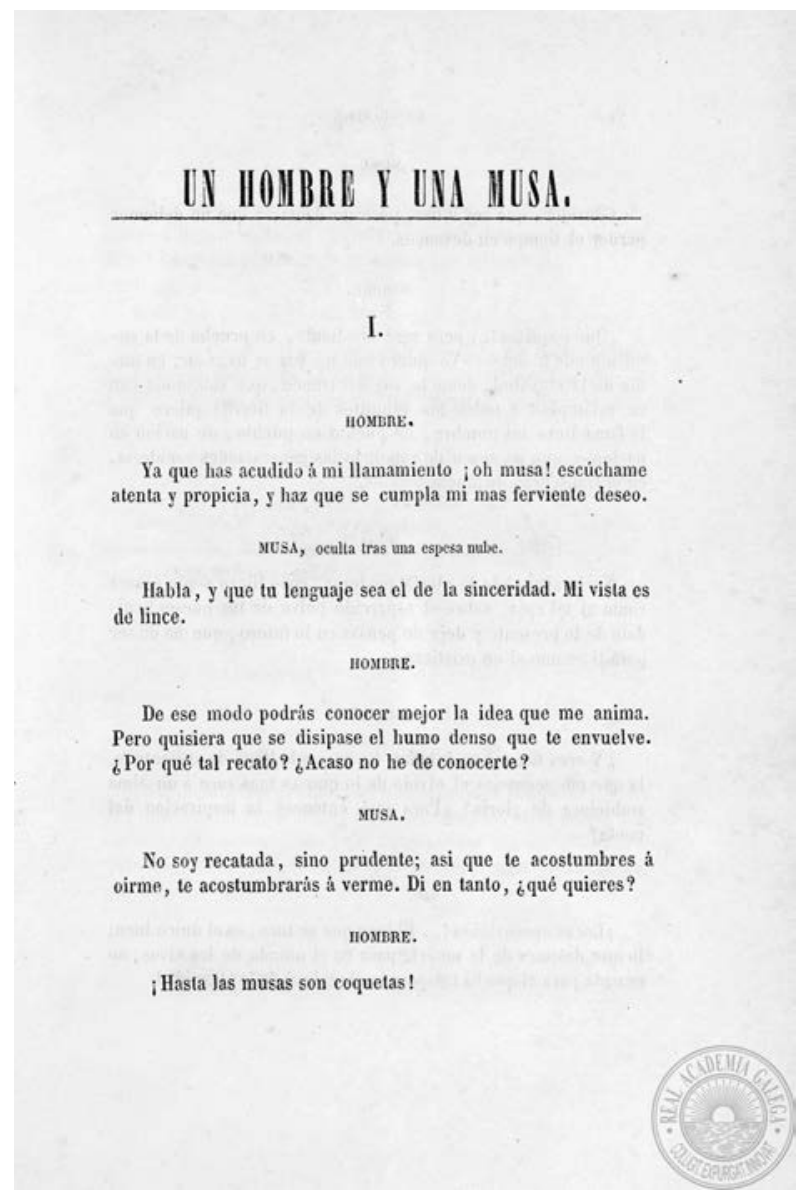

ILUSTRACIÓN 10: Primera página del prólogo autoral

como la Ilíada o la Odisea, las cuales se abrían con una invocación a la musa, el anuncio del asunto central (aquí, el deseo de gloria eterna por parte del Hombre) y la determinación del punto de partida narrativo (el Hombre, convertido ya en el inescrutable duque de la Gloria, es arrojado a la corte madrileña, en donde despierta la curiosidad y el deseo de todos, a quienes proclama su intención de «poner el cascabel al gato»). Asimismo, en cierto modo, el prólogo advierte del componente de primicia que posee la novela que está a punto de comenzar, estrategia retórica clásica. Las últimas líneas del preludio funcionan a manera de transición entre este texto preambular y el texto del cuento. Desaparecida ya la Musa, el Hombre detalla las nuevas sensaciones que le embargan tras conseguir su favor, así como surgen dos personajes en escena 
que se admiran de su apariencia, de manera que se pasa del mundo reflexivo al de la acción.

En definitiva, todo apunta a que «UN HOMBRE Y UNA MUSA» representa un marco poético imprescindible que facilita las claves esenciales de la novela que le sigue, como han defendido Fernández-Pérez Sanjulián (1986: 475), Gullón (1986: 488), Posada Alonso (1986: 493), March (1994: 232 y 242), Rodríguez (2011: 219) o Rábade Villar (2013: 52), en contra de la opinión de Poullain (1970: 47), quien lo contemplaba como una sección independiente. En contraste - he aquí la originalidad de Castro-, al mismo tiempo, la autora disuade de antemano al lector en el prólogo de buscar sentido a su novela y de aprehenderla correctamente ${ }^{24}$, con lo que deconstruye el propio género de prólogo, uno de cuyos cometidos es el de orientar hacia una buena interpretación del texto.

Desde luego, el prólogo y el relato conforman dos niveles narrativos íntimamente relacionados y dependientes el uno del otro. La lectura de la novela sería diferente sin su umbral —echando mano de la terminología borgiana-, que desafía de algún modo al discreto lector. Desde cierto prisma, Rosalía de Castro nos está abriendo las puertas de su taller al presentarnos los antecedentes del que va a convertirse de inmediato en protagonista de su novela. Gracias al prólogo, el receptor sabe que el héroe justiciero que satiriza las costumbres superficiales de la sociedad madrileña decimonónica - en particular, del mundo literario - y autor del sin par revelador Libro de los libros, no fue distinto de los codiciosos personajes burgueses que caricaturiza; es más, se contaba entre uno de ellos. Por tanto, la autora se está burlando de su propio personaje literario (en realidad, un exemplum ex contrario) y, por ende, de ella misma al exponer por adelantado que el superhombre que crea no está libre de pecado. De igual forma, el personaje de la Musa, identificado con la Novedad, anticipa el anhelo que vive la sociedad aristócrata y burguesa plasmada en la novela de nuevas tendencias, ya sean literarias, tecnológicas, de hábitos en la vestimenta o políticas, frente a los tediosos modelos contemporáneos dominantes.

\section{LA CITA DEL CAPÍTULO IV}

Tras el prólogo comienza la novela, cuyo título queda plasmado de nuevo antes del primer capítulo que, como todos los que siguen, es mudo, en cuanto que carece de epígrafe y cuenta con una titulación interna puramente numérica (Genette, 2001: 260). Solo en el cuarto capítulo el lector se topa, además de

24 «Los espectadores se devanarán los sesos por / comprender su argumento, y te juro que no lo / conseguirán, así como nadie los comprende a / ellos, sobre todo cuando [...] hacen que su / pobre ingenio se prodigue y desparrame / en miles de pliegos, vanamente escritos / pero perfectamente impresos» (Castro, 2000). 
con aquella indicación remática, con una cita autoral que precede al texto y que posee valor catafórico, esto es, de anuncio: «No hay función sin tarasca, / ni novela sin amores» (Ilustración 9). Estos versos explican, a modo metaliterario y como un guiño al lector —al igual que otro interesante pasaje del mismo capítulo (137) — , la obligación de la escritora de introducir la temática amorosa en su texto como novela que es, a la par que anticipa satíricamente la historia de amor, o más bien desamor, entre Mariquita y Melchor en la Corredera del perro, calle en donde Castro sitúa los estamentos sociales más bajos.

La sentencia «No hay función sin tarasca» aparece con anterioridad en el artículo rosaliano «Las literatas. Carta a Eduarda» (1866), en una serie enume-

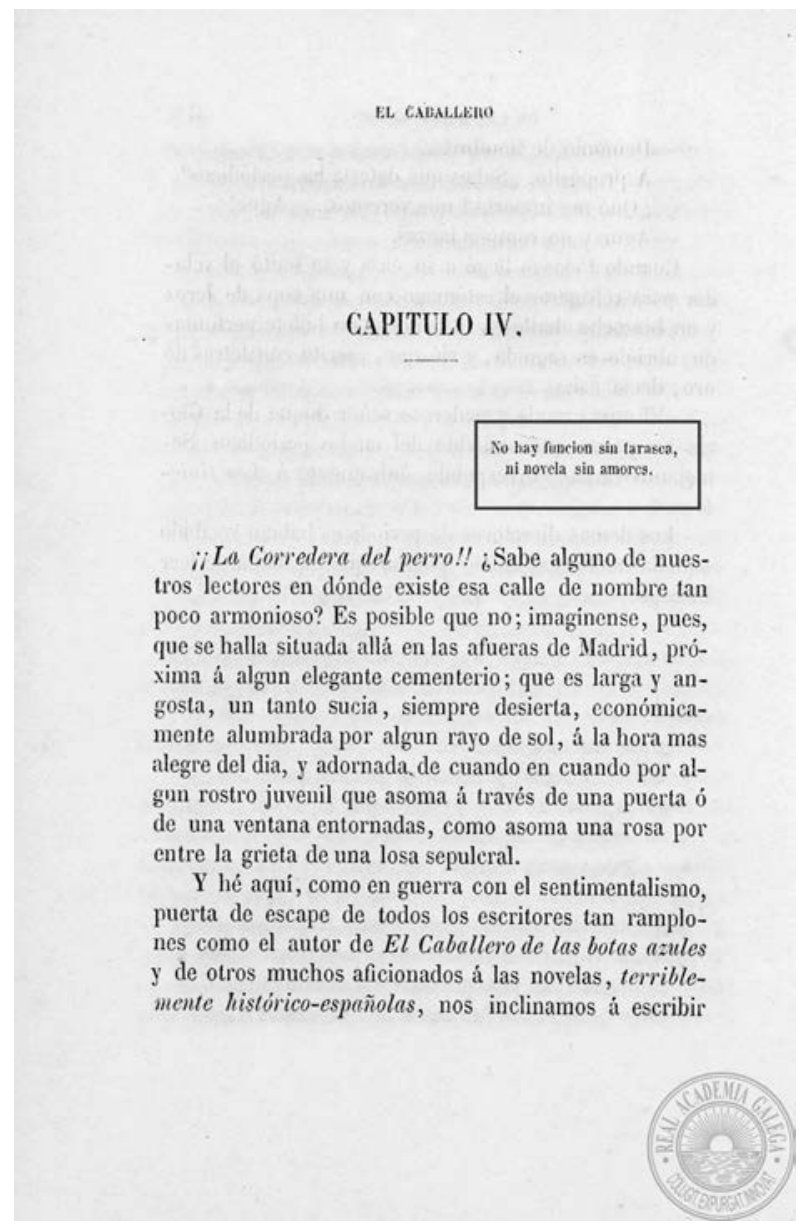

ILUSTRACIÓN 11: Primera página del capítulo IV 
rativa en la que la voz narradora aporta varios ejemplos a su receptora en los que la mujer literata siempre sale vilipendiada en el trato con la sociedad. $\mathrm{He}$ aquí en donde surge la máxima mencionada, que debe interpretarse a la luz del contexto burlesco en el que era tomada la figura de la escritora: «Si te agrada la sociedad, pretendes lucirte, quieres que se hable de ti, no hay función sin tarasca» $(1866: 57)^{25}$.

En conclusión, los paratextos que rodean El caballero de las botas azules están al servicio del texto al funcionar a modo de cicerone para el receptor. ¿Cómo se leería este relato rosaliano si no se titulara así, si careciera de una referencia paratitular autoral como «cuento extraño» o si no estuviera precedido por su controvertido prólogo? Sin duda, de una manera muy diferente. La novedad y la originalidad hacen acto de presencia ya desde los propios paratextos de esta novela, cuya lectura cobra plena vigencia en cualquier sociedad avanzada capitalista de nuestros días. No obstante, esos paratextos provocan simultáneamente confusión en el lector, cometido fundamental de la autora en esta desafiante obra — como percibieron lectores contemporáneos tan insignes y allegados a Castro como Murguía o Fernán Caballero-; si no, parafraseando a Umberto Eco (1985: 9): ¿para qué habría escrito la novela, que es siempre una máquina de generar interpretaciones?

\section{BIBLIOGRAFÍA CITADA}

Cabo Aseguinolaza, Fernando (2013). «Rosalía (post-)sublime: la autorreferencialidad en la obra narrativa de Rosalía de Castro», Boletín Hispánico Helvético. 22, pp. 151-170.

Castro, Rosalía de (1866). «Las literatas. Carta a Eduarda», en Almanaque de Galicia. Lugo: Imprenta de Soto Freire.

Castro, Rosalía de (1867). El caballero de las botas azules. Lugo: Imprenta de Soto de Freire.

Castro, Rosalía de (1931). El caballero de las botas azules. Barcelona: Juventud. N. ${ }^{\circ}$ extraordinario La Novela Rosa.

Castro, Rosalía de (1973). El caballero de las botas azules. Domingo García-Sabell (introd.). Madrid: Editorial Magisterio Español.

Castro, Rosalía de (1977). Obras completas, II. Madrid: Aguilar.

Castro, Rosalía de (1989). El caballero de las botas azules / La hija del mar. Vigo: Patronato Rosalía de Castro.

Castro, Rosalía de (1997). Bluestockings. K. March. Orono: Amaranta Press.

Castro, Rosalía de (2000). El caballero de las botas azules. A. Rodríguez-Fischer (ed.). Madrid: Cátedra.

Castro, Rosalía de (2013). El caballero de las botas azules. Barcelona: Barataria.

Charnon-Deutsch, Lou (1999). «Deseo y decadencia en El caballero de las botas azules», en L. Behiels y M. Steenmeijer (coord.), Asimilaciones y rechazos: presencias del Ro-

${ }^{25}$ La cursiva es mía. 
manticismo en el Realismo español del siglo XIX. Amsterdam/Atlanta: Editions Rodopi B.V., pp. 11-20.

Clúa Ginés, Isabel (2012). «De abismos y superficies: nuevos espacios de lo gótico en $E l$ caballero de las botas azules», en Helena González Fernández y María do Cebreiro Rábade (ed.), Canon y subversión. La obra narrativa de Rosalía de Castro. Barcelona: Icaria, pp. 159-177.

Davies, C. (1988). «El Caballero de las botas azules: Narrative Context and Intertextual Structure», en Antonio Carreño (ed.), Actas do Segundo Congreso de Estudios Galegos / Procedings of the Second Galician Congress. Homenaxe a José Amor y Vázquez (Brown University, noviembre 10-12). Vigo: Galaxia, pp. 21-33.

Díaz Marcos, Ana M. ${ }^{a}$ (2006). La edad de seda: representaciones de la moda en la literatura española (1728-1926). Cádiz: Universidad de Cádiz.

Eco, Umberto (1985). Apostillas a «El nombre de la rosa». Barcelona: Lumen.

Fernández-Pérez Sanjulián, Carme (1986). «O prólogo de El caballero de las botas azules ou o Ensaio dunha poética nova», en Actas do Congreso Internacional de estudios sobre Rosalía de Castro e o seu tempo. Santiago de Compostela: Consello da Cultura Galega / Universidade de Santiago de Compostela, I, pp. 475-482.

Genette, Gerard (2001). Umbrales. Susana Lage (trad.). México: Siglo Veintiuno editores.

Gullón, Germán (1986). «El caballero de las botas azules: farsa de las letras decimonónicas», en Actas do Congreso Internacional de estudios sobre Rosalía de Castro e o seu tempo. Santiago de Compostela: Consello da Cultura Galega, Universidade de Santiago de Compostela, I, pp. 483-491.

Hoek, Leo Huib (1981). La Marque du titre: Dispositifs sémiotiques d'une pratique textuelle. La Haye: Mouton.

March, Kathleen (1994). De musa a literata: el feminismo en la narrativa de Rosalía de Castro. Sada (A Coruña): Edicións do Castro.

March, Kathleen (2012). «¿Serían as súas verbas ou as súas vestimentas? Literatas de ambas as dúas orelas do Atlántico», Grial. 194, pp. 34-41.

Mecke, Jochen (2004). «Título, texto, hipertexto», en La literatura en la literatura. Actas del XIV Simposio de la Sociedad Española de Literatura General y Comparada, ed. M. León Gómez (Alcalá de Henares: Centro de Estudios Cervantinos), pp. 31-52.

Miguélez-Carballeira, Helena (2012). «¿Por qué Rosalía de Castro tenía razón? El caballero de las botas azules como texto antisistema», en Canon y subversión. La obra narrativa de Rosalía de Castro. Barcelona: Icaria, pp. 121-138.

Posada Alonso, Caridad (1986). «Modelo de elaboración del texto para El caballero de las botas azules», en Actas do Congreso Internacional de estudios sobre Rosalía de Castro e o seu tempo. Santiago de Compostela: Consello da Cultura Galega, Universidade de Santiago de Compostela, I, pp. 493-502.

Poullain, Claude (1970). «Valor y sentido de la novela de Rosalía de Castro de Murguía El caballero de las botas azules», Cuadernos de estudios gallegos. XXV, 75, pp. 37-69.

Rábade Villar, M. ${ }^{a}$ do Cebreiro (2013). «Alegoría y revolución. La política de la literatura en El caballero de las botas azules (1867)», Decimonónica. 10, 2, pp. 50-69.

Revilla, Federico (2010). Diccionario de iconografía y simbología. Madrid: Cátedra.

Rielo Carballo, Nicanor (1982). El libro lucense (1495-1936). Sada (A Coruña): Edicións do Castro.

Risco, Antón (1975). «El caballero de las botas azules, de Rosalía, una obra abierta», $P a-$ peles de Son Armadans, t. LXXVII, núm. CCXXX, pp. 113-130.

Risco, Antón (1986). «Unha novela fantástica de Rosalía: El caballero de las botas azules», en Actas do Congreso Internacional de estudios sobre Rosalía de Castro e o seu tempo. 
Santiago de Compostela: Consello da Cultura Galega, Universidade de Santiago de Compostela, I, pp. 449-455.

Rodríguez, Francisco (2011). Rosalía de Castro, estranxeira na súa patria (a persoa e a obra de onte a hoxe). [A Coruña]: Asociación Socio-Pedagóxica Galega.

Soto Freire, Manuel (1998). La imprenta en Galicia. Ensayo bibliográfico. X. R. Barreiro Fernández (intr., revisión del texto y notas). Santiago de Compostela: Xunta de Galicia. «Bibliofilia de Galicia», 13.

Vilavedra, Dolores (2012). «Rosalía de Castro: escribir desde la(s) frontera(s)», en Canon y subversión. La obra narrativa de Rosalía de Castro. Barcelona: Icaria, pp. 45-60.

Fecha de recepción: 2 de febrero de 2015.

Fecha de aceptación: 26 de junio de 2015. 